\title{
Comparative Investigation on the Concentrations of Dehydroepiandrosterone (DHEA) and Testosterone Levels in Infertile Males attending a Private University Teaching Hospital, in Rivers State, Nigeria
}

\section{${ }^{1}$ GEORGE-OPUDA, IM; ${ }^{* 2}$ ADEGOKE, AO; ${ }^{3}$ BAMIGBOWU, OE; ${ }^{2}$ NWAGANGA, C}

\author{
${ }^{I}$ Department of Medical Laboratory Science, Rivers State University, Port Harcourt, Nigeria \\ ${ }^{* 2}$ Department of Medical Laboratory Science, Madonna University, Elele, Nigeria \\ ${ }^{3}$ Department of Chemical Pathology, College of Medicine, University of Port Harcourt, Nigeria \\ *Corresponding Author Email: bayoadeghq@yahoo.com; Tel +2348037103687
}

\begin{abstract}
The study was carried out to determine the concentrations of Dehydroepiandrosterone hormone (DHEAS) and testosterone in infertile males and compared with fertile males attending Madonna University Teaching Hospital (MUTH) Elele. Thirty apparently infertile males and 30 apparently fertile male as control had their Dehydroepiandrosterone hormone (DHEAS) and testosterone determined using competitive immune enzymatic colorimetric method and Enzyme Immunoassay while the semen analysis was done using Microscopy method. There was significant increase $(\mathrm{P}<0.05)$ in DHEAS of $1.23 \pm 0.07 \mathrm{ug} / \mathrm{ml}$ obtained in infertile male compared with $3.78 \pm 0.13 \mathrm{ug} / \mathrm{ml}$ in the control. There was significant difference in Semen count of $56.27 \pm 2.82 \mathrm{million} / \mathrm{ml}$ in fertile males compared with $7.73 \pm 0.10 \mathrm{million} / \mathrm{ml}$ while testosterone in infertile males of $2.53 \pm 0.09$ was significantly lower than $7.52 \pm 0.31$ in fertile males $(\mathrm{P}<0.05)$. The study showed that DHEAS is elevated in infertility hence should be considered an indicator of infertility.
\end{abstract}

DOI: https://dx.doi.org/10.4314/jasem.v25i8.28

Copyright: Copyright $(0) 2021$ George-Opuda et al. This is an open access article distributed under the Creative Commons Attribution License (CCL), which permits unrestricted use, distribution, and reproduction in any medium, provided the original work is properly cited.

Dates: Received: 10 May 2021; Revised: 28 June 2021; Accepted: 01 July 2021

Keywords: Dehydroepiandrosterone, infertility, Testosterone, Semen, Immunoassay, colorimetric

There are a number of causes for male infertility, but they all affect quantity and/or quality of sperm. These causes include: The sperm's exit route is blocked (from birth, by scarring from infection, past vasectomy, etc.), Retrograde ejaculate (semen is ejaculated backwards, into the bladder), Sperm production in the testes is low or absent (there can be many causes for this finding), Low sperm count, also called oligospermia, is the most common cause of male infertility. Complete lack of sperm, called Azoospermia, is much less common, affecting less than $1 \%$ of the population. Low sperm count is diagnosed when the number of sperm falls below 20 million in a milliliter of semen. (Normal range is between 20 million and 120 million per milliliter of semen.) When sperm count is too low, sperm has a much lower chance of reaching and fertilizing the egg, leading to infertility (Kuohung et al., 2013). Many possible causes of low sperm count exist. Some are structural: even when sperm is produced normally in the testes, an obstruction in the ejaculation tract may block the sperm. Other causes include hormonal insufficiency, testicular injuries and chromosomal/genetic abnormalities (such as
Klinefelter syndrome). In addition, vasectomy can be considered a cause of male infertility, if the male partner changes his mind about having children after having had a vasectomy. One of the most common factors leading to decreased sperm count is varicocele. This is when the veins in the scrotum (the skin "sack" that contains the testicles) are dilated on one or both sides. This heats the inside of the scrotum excessively and may affect sperm production. Other factors can also include a blockage in a man's reproductive system, retrograde ejaculate and certain medications. Azoospermia is a condition in which the man has no sperm in the ejaculate. Families often assume that a diagnosis of Azoospermia rules out the possibility of having a child. However, with the treatments available today, that is not necessary the case.

Dehydroepiandrosterone (DHEA) is a steroid hormone produced by the adrenal glands in men and women. A hormone is a chemical produced in one part of the body that is carried to another part of the body where it has a specific effect. The adrenal glands are located on top of the kidneys. DHEA is the most 
common steroid in humans. It can be transformed in the body into testosterone (the primary male sex hormone), estrogen (an important female sex hormone), or other steroids. However, DHEA supplements have been shown not to increase testosterone in men. This effect is only seen in women (Arlt, 2004). DHEA leads to the production of androgens and estrogens (male and female sex hormones).DHEA is present in the body in two pools: "free" DHEA and the major circulating form, "sulfated" DHEA, or DHEAS. Because of its distribution in two large pools, it has been described as a "buffer" hormone, serving to prevent excesses or deficits of other important steroid hormones. DHEA also affects multiple physiologic systems in the body, including the central nervous system, the vascular system, the immune system and glucose metabolism. DHEA supplementation apparently significantly reduces $t$ age-related increases in aneuploidy (Gleicher et al., 2010) and, therefore, also reduces ageassociated increases in miscarriages (Gleicher et al., 2008 and Gleicher et al., 2010).With IVF cycles, older women produce few oocytes (Chuang et al., 2003; Orvieto et al., 2004) and yield few normal embryos when exposed to maximal gonadotrophin stimulation (Scott, 1996; Schoolcraft et al., 1997; Orvieto et al., 2004). This change in ovarian responsiveness is known as diminished ovarian reserve.

DHEA levels start relatively low at birth, and gradually increase until puberty, when levels increase markedly, reaching a peak around 20 to 24 years of age. From there, serum and tissue DHEA levels decline at a rate of 2 to $3 \%$ per year, with a steep decline occurring around middle age. By age 75, humans exhibit 10 to $20 \%$ of young adult DHEA levels. A number of review articles have summarized the available observational data showing that in older individuals' serum DHEA levels are inversely related to incidence and prevalence of disease (Copeland et al ., 2002). The aim of the study is to determine the concentrations of Dehydroepiandrosterone (DHEA) and testosterone in infertile males subjects attending Madonna University teaching hospital (MUTH).

\section{MATERIALS AND METHOD}

Subjects: The study was carried out on 30 infertile males (both primary and secondary infertility) within the age group 27-59 attending infertility clinic of Madonna University Teaching Hospital and 30 apparently fertile male (Control) of the same age range.

Sample Processing: Blood sample was collected from all subjects and control by venipuncture, separated into labelled bottles, and stored in the refrigerator till analysis. Also the patient was given a clean, dry, break-proof container and requested to collect a semen specimen following a 3 days abstinence and brought to laboratory for analysis.

Determination of Dehydroepiandrosterone sulphate Level: A 1:50 dilution where made by adding $25 \mathrm{mls}$ of distilled water to $5 \mathrm{mls}$ of serum diluent in a separate tube while the standard where not diluted. Using an automatic pipette, 980 microlitre of the diluted serum diluent where transferred into the micro titre wells plates and then 20microlitre of serum where added in each wells. Into 6 wells for standard 0-5,30microlitre of standard was added and 30microlitre of diluted samples where added into the wells for the samples. 100 microlitre of conjugate was added into standard wells and sample wells. Incubated for one hour, the wells where washed by moving the contents from each well with distilled water, washing was repeated by draining the water completely. 100microliter of TMB (tetra methyl benzidine) substrate was added into 6 wells for standard, wells for serum and blank. It incubated at room temperature (20-28) for 15minutes in the dark. Stop solution (sulphuric acid) was added into all wells to stop the blue colour reaction. The wells where shaken. The micro reader wavelength was set at $450 \mathrm{~nm}$ wavelength and the readings were taken while the unknown was extrapolated from the graph plotted using the values of the standard.

Determination of Testosterone Level: A 1:50 Dilutions where made by adding $25 \mathrm{mls}$ of distilled water to $5 \mathrm{mls}$ of serum diluent in a separate tube while the standard where not diluted. The desired number of wells were secured $\mathrm{n}$ the holder. 10ul of standards, sample and controls were dispensed into appropriate wells.50ul of rabbit anti testosterone reagent was dispensed to each well and mixed thoroughly.100ul of testosterone HRP Conjugate reagent was dispensed into each well and incubated at $37^{\circ} \mathrm{C}$ for 90 minutes.the wells where washed by removing the contents from each well with washing buffer, washing was repeated five times by draining the water completely. $100 \mu$ of TMB (Tetramethyl benzidine) substrate was added into all the wells and incubated at room temperature $\left(20-28^{\circ} \mathrm{C}\right)$ for 20 minutes. $100 \mu \mathrm{l}$ of stop solution (Sulphuric acid) was added into all wells to stop the bluecolour reaction. The wells were shaken and read at $450 \mathrm{~nm}$ wavelength using a microplate reader. The unknown was extrapolated from the graph plotted using the values of the standard.

Determination of Semen Analysis: The Volume of the semen produced was determined using a small graduated cylinder while the $\mathrm{pH}$ was measured using a narrow range $\mathrm{pH}$ paper. The motility of the semen 
was determined by putting a drop of well mixed liquefied semen on the slide and covered with a cover slip. The semen was examined under the microscope at X10 and X40 objectives while viable sperm was determined by a drop of semen and a drop of $0.5 \%$ eosin solution and examined under the microscope for unstained (Viable) at X10 and X40 objectives. Sperm count was done by adding 10ul of well mixed semen with 190ul (1:20) semen fluid diluents(Sodium bicarbonate formalin).It was mixed and a Neubauer ruled Chamber was charged with the well mixed diluted semen and allowed to settle for 2 minutes. The sperm cells were counted using the microscope at X10 objectives in an area of 2sq.millimeteri.e 2 large squares. The sperm count was calculated by multiplying the number counted by 100,000 . The percentage morphology was determined by staining with dilute carbol fuschin after fixing with ethanol and washed with sodium bicarbonate formalin to remove mucus present (Cheesbrough 2000).

Statistical Analysis: The biochemical data were subjected to some statistical analysis as the mean(x), standard deviation (SD), standard error of mean (SEM) and student's t-test using statistical package for social sciences (SSPS) version 17. The results were expressed in Mean+- standard error of mean (SEM).

\section{RESULTS AND DISCUSSION}

Semen count of $56.27 \pm 2.82(\mathrm{~m} / \mathrm{ml})$ in control is significantly lower than $7.73 \pm 0.10(\mathrm{~m} / \mathrm{ml})$ in infertile males subjects $(\mathrm{P}<0.05)$ while there was significant difference $(\mathrm{P}>0.05)$ in testosterone levels $(\mathrm{ng} / \mathrm{ml})$ of $7.52 \pm 0.31$ in control and $2.53 \pm 0.09$ in infertile males subjects. Also, the DHEAS levels $(\mu \mathrm{g} / \mathrm{ml})$ of 3.78 \pm 0.13 in control was significant difference $(p<0.05)$ from the $1.23 \pm 0.07$ in infertile males subjects as shown in table 1below. The result of study showed that there was significant difference $(p<0.05)$ in the semen count of infertile males compared with the controls. The result also showed that there was significant difference $(\mathrm{P}<0.05)$ in the DHEAS of infertile males compared with their control. This is similar to study by Lindschau, et al.,( 2011). Adegoke et al (2015) in their study showed that DHEAS was elevated in female infertility hence should be considered an indicator of infertility. The result of study further showed that there was significant difference $(\mathrm{P}<0.05)$ in the testosterone concentration of the infertile males compared with the control. Testosterone is a male sex hormone that is important for sexual and reproductive development. The hormone also plays a role in sex drive, sperm production, fat distribution, red cell production, and maintenance of muscle strength and mass. This is similar to the study by Lombardo et al (2005) who reported that severe defects of the Antibody response may result in abnormal male sexual development, while more subtle modifications can be a potential cause of male infertility. Low circulating levels of testosterone can be found in $20-30 \%$ of infertile men, but administration of testosterone or gonadotropins does not result in improved sperm production (Lombardo et al., 2005). The result also showed that there was significant difference in sperm count, testosterone and DHEAS in different age groups of infertile men compared with their respective controls. This is similar to the study by Feldman, et al (2002) who reported that the increase in sex hormonebinding globulin (SHBG) likely results in a further decrease in testosterone levels.

Table 1: DHEAS and Testosterone concentrations in infertile males

\begin{tabular}{|c|c|c|c|c|}
\hline Parameter & Control & Infertile male & t & $\mathbf{P}$ \\
\hline Semen Count $\left(\right.$ X 10 $\left.10^{9} / \mathrm{l}\right)$ & $56.27 \pm 2.82$ & $7.73 \pm 0.10$ & 53.22 & 0.000 \\
\hline Testosterone (ng/ml) & $7.52 \pm 0.31$ & $2.53 \pm 0.09$ & 47.343 & 0.000 \\
\hline DHEAS(ug/ml) & $3.78+0.13$ & $1.23 \pm 0.07$ & 50.502 & 0.000 \\
\hline
\end{tabular}

There was significant difference in the semen count $(\mathrm{m} / \mathrm{ml})$ of $56.83 \pm 4.16,57.95 \pm 3.93$ and $47.00 \pm 3.24$ obtained in male control at age 27-37, 38-48 and 4959 respectively $(\mathrm{p}<0.05)$. There was significant difference in the testosterone levels $(\mathrm{ng} / \mathrm{ml})$ of $8.22 \pm$ $0.86,7.44 \pm 0.38$ and $6.90 \pm 0.53$ obtained in male control at age $27-37,38-48$ and $49-59$ respectively $(\mathrm{p}<0.05)$. There was significant difference in the DHEAS levels $(\mu \mathrm{g} / \mathrm{ml})$ of $3.86 \pm 0.42,3.76 \pm 0.15$ and $3.72 \pm 0.42$ obtained in male control at age $27-37,38$ 48 and $49-59$ respectively $(\mathrm{p}<0.05)$. There was significant difference in the semen count of $7.87 \pm$ $0.97,6.13 \pm 1.56$ and $11.00 \pm 2.16$ obtained in infertile male at age of $27-37,38-48$ and $49-59$ respectively $(\mathrm{p}<0.05)$. There was significant difference in the testosterone levels $(\mathrm{ng} / \mathrm{ml})$ of $2.59 \pm 0.19,2.54 \pm 0.12$ and $2.44 \pm 0.21$ obtained in infertile male at 27-37, 3848 and $49-59$ respectively $(\mathrm{p}<0.05)$. There was significant difference in the DHEAS levels $(\mu \mathrm{g} / \mathrm{ml})$ of $1.20 \pm 0.16,1.22 \pm 0.10$ and $1.30 \pm 0.18$ obtained in infertile male at age of $27-37,38-48$ and 49-59 respectively $(p<0.05)$. Low levels of DHEA are associated with aging and cardiovascular disease in men (Thijs et al., 2003). Also Sasano, and Ichijo, (1969) first described the decrease in sperm concentration as men age. They reported that $90 \%$ of seminiferous tubules in men in their 20 s and 30 s contained spermatids, whereas men in their $40 \mathrm{~s}$ and 50 s had spermatids in $50 \%$ of their seminiferous tubules. Only $10 \%$ of seminiferous tubules from men 
aged > 80 years contained spermatids (Sasano and Ichijo 1969). The most common reasons for laboratory semen analysis in humans are as part of a couple's

Table 2: DHEAS and Testosterone concentrations in different age groups of infertile

\begin{tabular}{lllll}
\multicolumn{4}{c}{ males } \\
\hline Treatment & $\begin{array}{l}\text { Age } \\
\text { Group } \\
\text { (Years) }\end{array}$ & $\begin{array}{l}\text { Semen count } \\
(\mathrm{X} \mathrm{10} / \mathrm{l})\end{array}$ & $\begin{array}{l}\text { Testosterone } \\
(\mathrm{ng} / \mathrm{ml})\end{array}$ & $\begin{array}{l}\text { DHEAS } \\
\text { (ug/ml) }\end{array}$ \\
\hline Control & $27-37$ & $56.83 \pm 4.16$ & $8.22 \pm 0.86$ & $3.86 \pm 0.42$ \\
& $38-48$ & $57.95 \pm 3.93$ & $7.44 \pm 0.38$ & $3.76 \pm 0.15$ \\
& $49-59$ & $47.00 \pm 3.24$ & $6.90 \pm 0.53$ & $3.72 \pm 0.42$ \\
Infertile & $27-37$ & $7.87 \pm 0.97$ & $2.59 \pm 0.19$ & $1.20 \pm 0.16$ \\
& $38-48$ & $6.13 \pm 1.56$ & $2.54 \pm 0.12$ & $1.22 \pm 0.10$ \\
& $49-59$ & $11.00 \pm 2.16$ & $2.44 \pm 0.21$ & $1.30 \pm 0.18$ \\
& F & 53.222 & 47.343 & 50.502 \\
& P & 0.000 & 0.000 & 0.000 \\
\hline Post Hoc & & & & \\
\hline $27-37$ & $38-48$ & 1.000 & 0.996 & 1.000 \\
& $49-59$ & 0.637 & 0.919 & 1.000 \\
& $27-37$ & 0.000 & 0.009 & 0.008 \\
& $38-48$ & 0.000 & 0.010 & 0.011 \\
$38-48$ & $49-59$ & 0.000 & 0.008 & 0.009 \\
& $27-37$ & 1.000 & 0.996 & 1.000 \\
& $49-59$ & 0.449 & 0.997 & 1.000 \\
& $27-37$ & 0.000 & 0.000 & 0.000 \\
& $38-48$ & 0.000 & 0.000 & 0.000 \\
$49-59$ & $49-59$ & 0.000 & 0.000 & 0.000 \\
& $27-37$ & 0.637 & 0.919 & 1.000 \\
& $38-48$ & 0.449 & 0.997 & 1.000 \\
& $27-37$ & 0.004 & 0.015 & 0.038 \\
& $38-48$ & 0.002 & 0.019 & 0.049 \\
& $49-59$ & 0.001 & 0.012 & 0.042 \\
& $27-37$ & 0.000 & 0.009 & 0.008 \\
& $38-48$ & 0.000 & 0.000 & 0.000 \\
& $49-59$ & 0.004 & 0.015 & 0.038 \\
& $38-48$ & 0.996 & 1.000 & 1.000 \\
& $49-59$ & 0.908 & 1.000 & 1.000 \\
& $27-37$ & 0.000 & 0.010 & 0.011 \\
& $38-48$ & 0.000 & 0.000 & 0.000 \\
& $49-59$ & 0.002 & 0.019 & 0.049 \\
& $27-37$ & 0.996 & 1.000 & 1.000 \\
& $49-59$ & 0.640 & 1.000 & 1.000 \\
& $27-37$ & 0.000 & 0.008 & 0.009 \\
& $38-48$ & 0.000 & 0.000 & 0.000 \\
& $49-59$ & 0.001 & 0.012 & 0.042 \\
& $27-37$ & 0.908 & 1.000 & 1.000 \\
& $38-48$ & 0.640 & 1.000 & 1.000 \\
\hline & & & &
\end{tabular}

Conclusion: This study shows that there is decrease in semen analysis, testosterone and DHEAS in infertile males than fertile males. Therefore semen analysis, testosterone and DHEAS of infertile males should be determined in diagnosis of infertility and treated to increase the chances of reversing infertility.

\section{REFERENCES}

Adegoke, OA; Brisibe, TP; Ofonime, AU; Ekwusa, VO (2015). Concentration of Dehydroepiandrosterone (DHEAS) In Infertile Women Attending Madonna University Teaching Hospital. Afri. J. Cellular Pathology 5: 1- 4

Arlt, W (2004). Dehydroepiandrosterone and ageing. Best practice \& research. Clinical Endocrinology \& Metabolism 18 (3): 363-380
Cheesbrough, M (2000).

Examination of semen in:

District Laboratory Practice in

Tropical Countries, Part 2

Cambridge University Press, U.K., pp. 130-132.

Chuang, CC; Chen, CD; Chao, KH; Chen, SU; Ho, HN; Yang, YS (2003). Age is a better predictor of pregnancy potential than basal follicle stimulating hormone levels in women undergoing in vitro fertilization. Fertility and Sterility.79:63-68.

Copeland, JL; Consitt, LA; Tremblay, MS (2002). Hormonal Responses to Endurance and Resistance Exercise in Females Aged 19-69 Years. Journal of Gerontology. American. Biology. Sci. Med. 57 (4): $158-165$.

Feldman, HA; Longcope, C; Derby, CA; Johannes, CB; Araujo, AB; Coviello, AD; Bremner, WJ; McKinlay, JB ( 2002). Age trends in the level of serum testosterone and other hormones in middle-aged men: longitudinal results from the Massachusetts male aging study. J. Clinical Endocrinology and Metabolism. 87:589-98.

Gleicher, N; Weghofer, A; Barad, DH (2010).Dehydroepiandrosterone (DHEA) reduces embryo aneuploidy: Direct evidence from preimplantation genetic screening (PGS).Reproductory Bioliogical Endocrinol. 8:140.

Gleicher, N; Weghofer, A; Barad, D (2008). Preimplantation screening: established and ready for prime time? Fertility and Sterility. 89:780-788

Kuohung, W; Greg, M; Kolbert, DL (2013). Causes of female infertility.

http://www.uptodate.com/home. Accessed May 22, 2013. 
Lombardo, T; Appleby, P; Barnes, I; Reeves, G (2005). Endogenous sex hormones and infertility. J. Neology Cancer Institution. 94 (8): 606-616.

Lindschau, C; Kirsch, T; Klinge, U; Kolkhof, P; Peters, I; Fiebele, A (2011). Dehydroepiandrosterone-induced phosphorylation and translocation of FoxO1 depend on the mineralocorticoid receptor. Hypertension. 58: (3): 471-478

Orvieto, R; Bar-Hava, I; Yoeli, R; Ashkenazi, J; Rabinerson, D; Bar, J; Fisch, B (2004). Results of in vitro fertilization cycles in women aged 43-45 years. Gynaecology of Endocrinology. 18:75-78.

Sasano, N; Ichijo S (1969). Vascular patterns of the human testis with special reference to its senile changes. Tohoku Journal of Experimental Med. 99:269-80.
Schoolcraft W; Schlenker T; Gee M; Stevens J; Wagley L (1997). Improved controlled ovarian hyperstimulation in poor responder in vitro fertilization patients with a microdose follicle stimulating hormone flare, growth hormone protocol. Fertility and Sterility. 67:93-97

Scott, RT Jr (1996). Evaluation and treatment of low responders. Semin Reproduction of Endocrinology. 14:317-337.

Thijs, L; Fagard, R; Forette, F; Nawrot, T; Staessen, JA (2003). Are low dehydroepiandrosterone sulphate levels predictive for cardiovascular diseases? A review of prospective and retrospective studies. Acta Cardiology.58 (5): 403-10 